\title{
CARACTERIZAÇÃO PETROGRÁFICA DAS ROCHAS ENCAIXANTES DA MINERALIZAÇÃ̃O AURÍFERA DO DEPÓSITO LAVRA VELHA - REGIÃO DE IBITIARA, BORDA OESTE DA CHAPADA DIAMANTINA, BAHIA.
}

\author{
PETROGRAPHIC CHARACTERIZATION OF THE GOLD MINERALIZATION HOST ROCKS OF \\ THE LAVRA VELHA DEPOSIT - IBITIARA REGION, WESTERN EDGE OF CHAPADA \\ DIAMANTINA, BAHIA.
}

\author{
Aline de Cassia CARLIN ${ }^{1}$, Antenor ZANARDO ${ }^{2}$, Guillermo Rafael Beltran NAVARRO² \\ ${ }^{1}$ Pós-Graduação em Geociências e Meio Ambiente, Instituto de Geociências e Ciências Exatas, Universidade Estadual Paulista, \\ UNESP, Rio Claro (SP). Email: alinecarlin@yahoo.com.br \\ ${ }^{2}$ Instituto de Geociências e Ciências Exatas, Universidade Estadual Paulista, UNESP, Rio Claro (SP). \\ Emails: zanardo@rc.unesp.br; navarro@rc.unesp.br

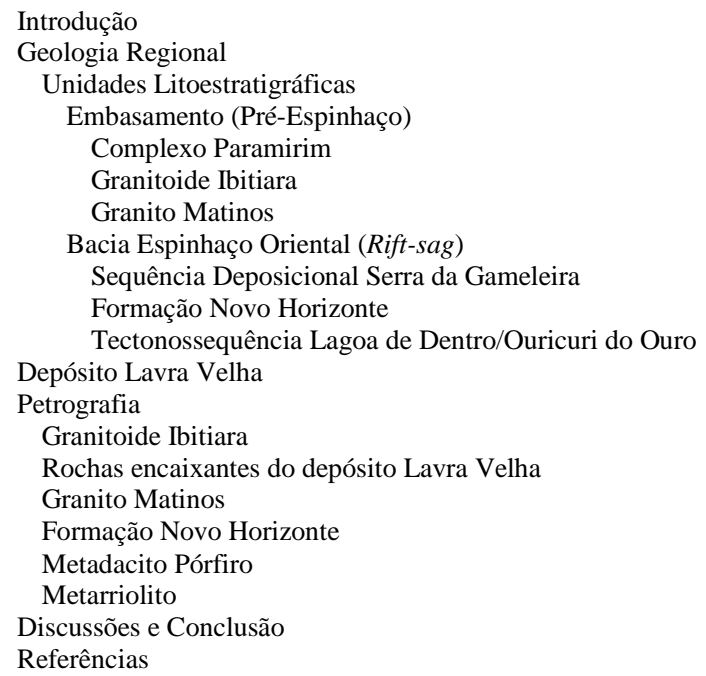

RESUMO - O depósito de ouro Lavra Velha localiza-se na cidade de Ibitiara, centro-oeste do Estado da Bahia e borda oeste do domínio fisiográfico da Chapada Diamantina, situado no Aulacógeno do Paramirim, região norte do Cráton São Francisco. O depósito, cuja mineralização se hospeda em brechas hematíticas sericitizadas, foi recentemente inserido na classe de modelo IOCG (Iron Oxide Cooper Gold). O principal objetivo do trabalho foi caracterizar petrograficamente as rochas encaixantes deste depósito, cujas litologias predominantes são metatonalitos e meta-quartzo diorito. Estas rochas encontram-se completamente alteradas, com atuação dos processos hidrotermais predominando sobre a deformação de baixo strain, resultando principalmente em intensa sericitização e formação de óxidos de ferro. A análise petrográfica, sugere que as rochas encaixantes do depósito são correspondentes alteradas do Granitoide Ibitiara, metamorfizadas, deformadas e alteradas hidrotermalmente. A intrusão do Granitoide Ibitiara ocorre, provavelmente, em ambiente mais raso da crosta, sugerindo que fluidos hidrotermais e mineralizantes sejam mais tardios. Apesar de integrado até o momento à classe de depósitos IOCG, a análise tectono-estrutural e hidrotermal do depósito Lavra Velha sugere que a mineralização de ouro tenha origem relacionada à fase mais tardia de evolução da bacia do Espinhaço, relacionada à inversão do aulacógeno do Paramirim.

Palavras-chave: Depósito Lavra Velha; Cráton São Francisco; Aulacógeno do Paramirim; Depósito IOCG; Supergrupo Espinhaço.

\begin{abstract}
The Lavra Velha gold deposit is located in Ibitiara, Bahia's central west and the western edge of the physiographic domain of the Chapada Diamantina, situated in Paramirim aulacogen, in northern of São Francisco Craton. The deposit, whose hematite sericitic breccias is hosting the mineralization, was recently insert into the IOCG model class (Iron Oxide Cooper Gold). The main objective of the study was the petrographic characterization of the host rocks of the Lavra Velha deposit, whose predominant lithologies are meta-tonalites and meta-quartz diorite. These rocks are completely altered due to hydrothermal process, which predominates under the deformation at low-strain rate, resulting manly in intense sericitization and iron oxide formation. The petrographic analysis suggests that the deposit's host rocks correspond to metamorphosed, deformed and hydrothermalized portion of Ibitiara Granitoid. The Ibitiara Granitoid intrusion probably occurs at a shallower crust environment, suggesting that the hydrothermal and mineralizer fluids are later. In spite of the Lavra Velha deposit has being classified as IOCG's class, the tectonic, structural and hydrothermal analysis suggests that the gold mineralization has originated during Espinhaço basin later deformation stage, related to inversion of the Paramirim aulacogen.
\end{abstract}

Keywords: Lavra Velha deposit; São Francisco Craton; Paramirim Aulacogen; IOCG deposits; Espinhaço Supergroup.

\section{INTRODUÇÃO}

O Depósito Lavra Velha consiste em uma ocorrência auro-cuprífera localizada na região central do Estado da Bahia, próximo ao município de Ibitiara, a aproximadamente 500 km de Salvador (Figura 1).

O depósito estudado está inserido no 
domínio fisiográfico da Chapada Diamantina e Aulacógeno do Paramirim, porção setentrional do Cráton do São Francisco, sobre o qual estão depositadas as rochas metavulcanossedimentares do Supergrupo Espinhaço, que ocorrem na região do depósito de Lavra Velha.

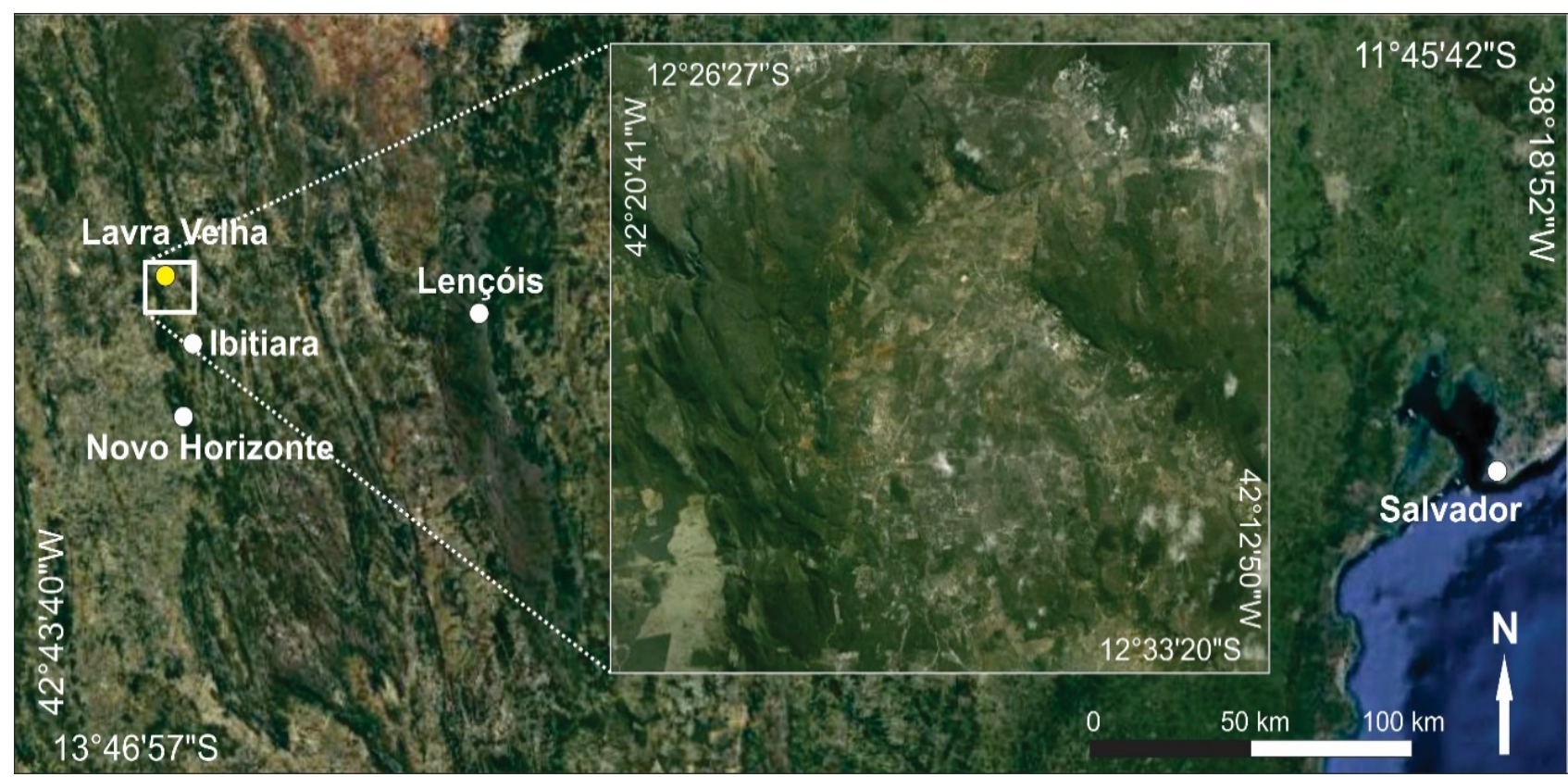

Figura 1 - Mapa de localização do Depósito Lavra Velha, com sua área detalhada no centro da imagem, a norte do município de Ibitiara (BA) e oeste da capital Salvador.

Segundo Guimarães et al. (2005), ocorrências de mineralização de ouro na região de Ibitiara associam-se a veios de quartzo boudinados, ao longo de zonas de cisalhamento, com direção geral em NNWSSE. Segundo estes autores, os veios auríferos interceptam rochas da Formação Serra da Gameleira, Grupos Rio dos Remédios e Paraguaçu, além do Granitoide paleoproterozoico de Ibitiara (Mina Beta do Tatu). Até o momento poucos trabalhos acerca do Depósito Lavra Velha foram desenvolvidos, tendo por conhecimento Carlin (2013) e Campos (2013), que apresentam diversas lacunas quanto ao modelo evolutivo e metalogenético proposto.

Segundo Campos (2013), a mineralização de cobre e ouro Lavra Velha está associada a brechas hidrotermais sulfetadas e hematíticas e é classificada na classe de modelo de depósito do tipo IOCG (Iron Oxide CopperGold).

Previamente aos trabalhos de Campos (2013) e Carlin (2013), a equipe de geólogos de exploração da empresa Yamana Gold, que detém os direitos de pesquisa mineral da área, acreditava que as rochas encaixantes da mineralização tinham origem vulcânica e subvulcânica (riolitos, dacitos e tufos) correlacionáveis à Formação Novo Horizonte, sendo esta unidade o principal foco para a prospecção mineral na época.

Porém, trabalhos de campo e análises petrográficas, discorridos neste trabalho, indicam semelhanças entre as rochas encaixantes e o embasamento Granitoide Ibitiara.

O principal objetivo desta pesquisa foi caracterizar petrograficamente as rochas encaixantes do depósito Lavra Velha. Foram selecionadas amostras de afloramento e de testemunhos de furo de sondagem da empresa Yamana Gold para confecção das lâminas em seções delgadas polidas no Laboratório de Laminação do Departamento de Petrologia e Metalogenia (DPM) do Instituto de Geociências e Ciências Exatas (IGCE), na Universidade Estadual Paulista "Júlio de Mesquita Filho”, Campus de Rio Claro. As lâminas petrográficas foram analisadas nos microscópios petrográficos/ metalográficos de luz refletida e transmitida, das marcas ZEISS Axioskop 40 e Leica, do Laboratório de Fotomicroscopia do Departamento de Petrologia e Metalogenia (DPM) da Unesp, Campus de Rio Claro. 


\section{GEOLOGIA REGIONAL}

Segundo Cruz \& Alkmim (2006), o depósito de ouro e cobre Lavra Velha localiza-se no domínio fisiográfico da Chapada Diamantina, norte do Cráton São Francisco, na região central do Estado da Bahia e domínio morfotectônico do Aulacógeno do Paramirim (Figura 2).

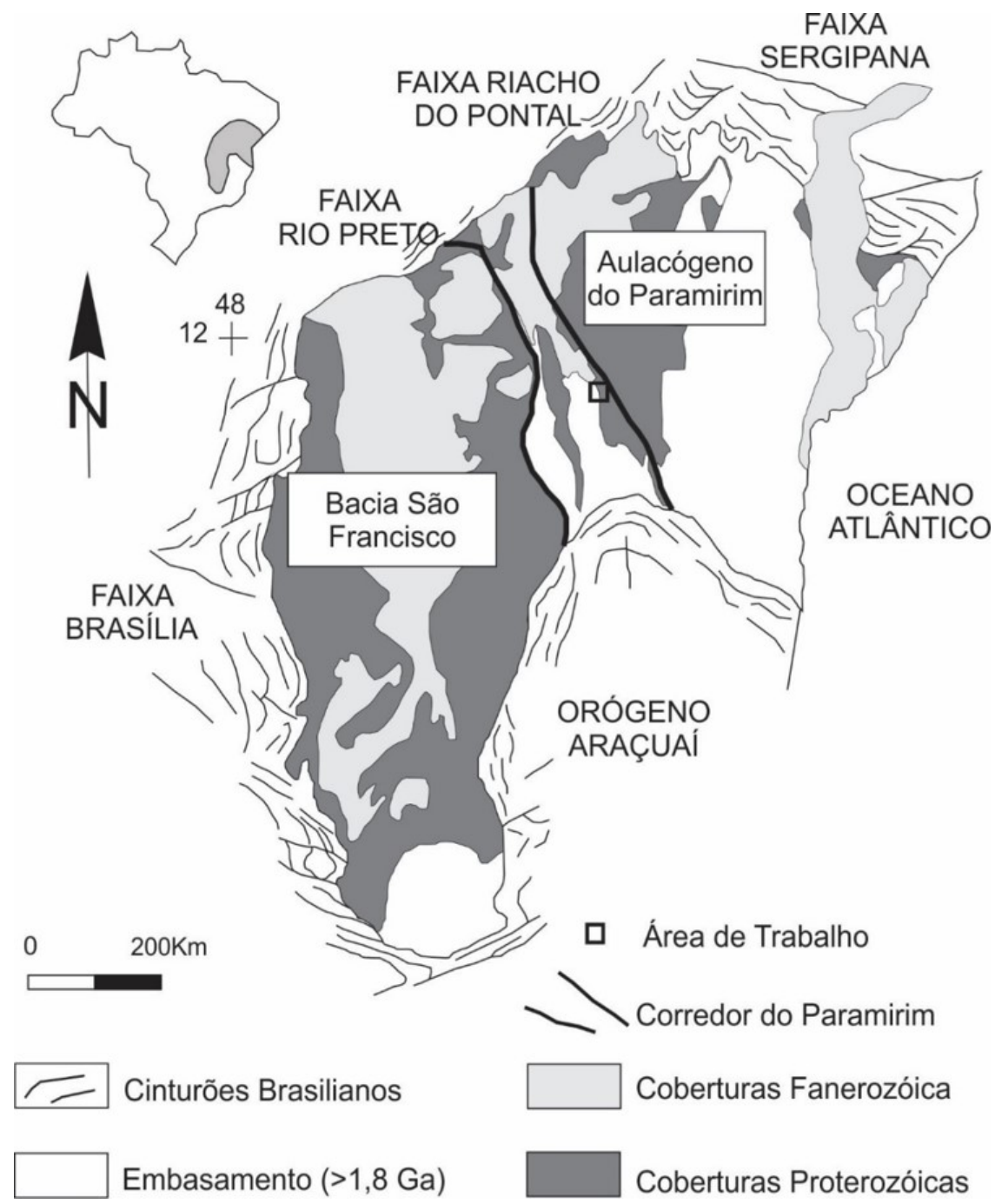

Figura 2 - O depósito Lavra Velha, em destaque pelo retângulo preto, localiza-se no Aulacógeno do Paramirim, porção setentrional do Cráton São Francisco. Modificado de Cruz \& Alkimin (2006).

O Aulacógeno do Paramirim corresponde a uma estrutura de direção NNW, que segundo Pedrosa-Soares et al. (2001), evolui a partir de rifts superpostos e parcialmente invertidos, de idade paleo- a neoproterozoica.

O embasamento do Aulacógeno do Paramirim insere-se no domínio no Bloco Gavião, que segundo Bastos Leal et al. (1998), corresponde ao segmento de rochas mais antigas do cráton São Francisco, com idades modelo de $\mathrm{Sm} / \mathrm{Nd}$ variando entre 3,3 e 3,7 Ga, constituído principalmente por tonalitos-trondhjemitosgranodioritos (TTGs) arqueanos, rochas metassedimentares e granitoides paleoproterozoicos, intrudidas por suítes graníticas mais jovens que 1,8 Ga (Cruz, 2004; Cruz \&
Alkmim, 2006). A partir do Paleoproterozoico, a evolução do aulacógeno se inicia com a formação de rifts intracratônicos abortados, ao longo de falhas com orientação N-S a NW-SE, sobre o qual se instalou o Supergrupo Espinhaço (Schobbenhaus, 1996). No Brasiliano, sua interação tectônica com a Faixa Araçuaí e a colisão dos crátons Amazônico e São Francisco resultaram na inversão parcial do Aulacógeno, como consequência do encurtamento WSWENE. Segundo Cruz (2004), as estruturas distensionais são progressivamente invertidas para o sul do aulacógeno.

De acordo com Alkmim et al. (1993), Cruz (2004) e Cruz \& Alkmim (2006), uma zona de máxima inversão secciona o aulacógeno na 
direção NNW-SSE e corresponde ao Corredor do Paramirim. Segundo Alkmim et al. (1993), a origem do Corredor do Paramirim está associada ao embricamento de cunhas do embasamento sob as rochas supracrustais ao longo do eixo do rift. Esta estrutura abrange as rochas dos supergrupos Espinhaço e São Francisco nas bacias do Espinhaço setentrional e São Francisco.

\section{Unidades Litoestratigráficas}

Segundo Guimarães et al. (2005), a região do depósito Lavra Velha é representada geologicamente por uma sequência de rochas arqueanas, seguidas por associações plutonovulcanossedimentares de idade paleo- a mesoproterozoica e intrusões de rochas máficas.

De acordo com estes autores, o embasamento arqueano corresponde ao Complexo Paramirim, representado por ortognaisses migmatíticos, com intrusões graníticas paleoproterozóicas, correspondente ao Granitoide Ibitiara. Sobre o embasamento, do Estateriano ao Callimiano (1800-1400 Ma), foram implantadas duas bacias intracratônicas superpostas e diacrônicas: uma do tipo rift-sag (Bacia do Espinhaço Oriental), onde se situa a área do depósito, e outra do tipo sinéclise (Bacia Chapada Diamantina).

As fases de evolução da Bacia do Espinhaço Oriental (rift-sag) são pré-rifte, sin-rifte e pósrifte. A fase pré-rifte corresponde ao estiramento flexural da crosta, com deposição de sedimentos da Formação Serra da Gameleira, na base do Supergrupo Espinhaço. Na fase sin-rifte são depositadas rochas vulcânicas, subvulcânicas e sedimentares que constituem o Grupo Rio dos Remédios, formado pelas tectonossequências Novo Horizonte e Lagoa de Dentro/Ouricuri do Ouro. Os sedimentos da Supersequência Mangabeira/Açuruá, que não ocorre na área do depósito Lavra Velha, caracterizam a fase pósrifte.

\section{Embasamento (Pré-Espinhaço)}

\section{Complexo Paramirim}

O Complexo Paramirim (PaleoMesoarqueano) é representado na região do depósito Lavra Velha por ortognaisses migmatíticos e ortognaisses granodioríticos (Arcanjo et al., 2000). Segundo Guimarães et al. (2005), ocorrem tonalitos, granodioritos e monzogranitos, com sienogranitos e sienitos subordinados, podendo apresentar migmatitos bandados, schlieren ou nebulíticos. De acordo com Teixeira (2000), as rochas são cálcio- alcalinas potássicas e peraluminosas, prováveis produtos de fusão parcial de uma crosta de composição TTG, com contribuição sedimentar. De acordo com Guimarães et al. (2005) apresentam foliações orientadas a NW-SE e N-S com fortes mergulhos para sudoeste e oeste.

Granitoide Ibitiara

O Granitoide Ibitiara é representado por dioritos, tonalitos e granitos cálcio-alcalinos, sódicos e peraluminosos, datada, pelo método UPb em zircões por Teixeira (2005), em 2091 $\pm 6,6$ Ma (Guimarães et al., 2005). Para este autor, estas rochas têm origem relacionadas à fusão parcial de manto metassomatizado em ambiente de arco magmático.

Segundo Guimarães et al. (2005) também ocorre na unidade granodiorito porfirítico com fenocristais de quartzo e feldspato sericitizados e xenólitos de biotita gnaisse. O hidrotermalismo é evidenciado pelos processos de epidotização, potassificação e sericitização.

Guimarães et al. (2005) associam à esta unidade a mineralização aurífera da "mina” Beta Tatu, cujo minério de ouro ocorre em veios de quartzo descontínuos, fraturados, associados a óxidos de ferro e encaixados em rochas cisalhadas e intemperizadas.

\section{Granito Matinos}

O Granito Matinos é representado por granodioritos e granitos, predominantemente monzogranitos, porfiríticos, foliados a gnáissicos, com termos tonalíticos subordinados (Guimarães et al., 2005). Segundo Teixeira (2005), são rochas metaluminosas a peraluminosas, potássicas, do tipo A. A datação de uma amostra de biotita granito, pelo método U-Pb em zircão realizada por Campos (2013), forneceu idade de 2,18 Ga para a unidade.

De acordo com Arcanjo et al. (2000), os granitoides estão associados a uma deformação bastante heterogênea, com granitoides isotrópicos a foliados, ortognaisses e ortognaisses protomiloníticos a miloníticos. Delgadas zonas de cisalhamento dúcteis de direção geral NNW-SSE, subverticais para WSW, associam-se a granitoides completamente transformados, que constituem corredores de quartzo-sericita-clorita xistos.

De acordo com Guimarães et al. (2005), ocorre mineralizações de cobre no Granito Matinos, associadas a minerais de malaquita, crisocola, azurita, calcopirita, bornita e calcosita 
em filões de quartzo com magnetita, limonita e carbonatos de zonas de falhas com direção E-W ou em veios de quartzo brechados com óxidos de cobre associado. Ainda segundo os autores, brechas hidrotermais, formadas por fragmentos de quartzo e hematita/magnetita marcam o contato entre o veio e o granitoide encaixante.

\section{Bacia Espinhaço Oriental (Rift-Sag)}

Sequência deposicional Serra da Gameleira

Segundo Guimarães et al. (2005), a Sequência Deposicional, ou Formação Serra da Gameleira é formada por associações de litofácies siliciclásticas continentais, depositados em ambiente desértico.

A sequência é representada por quartzo metarenito bimodal, metagrauvaca e metarcóseos, associados à metaconglomerado polimítico, metaconglomerado oligomítico, metarenitos e metabrechas de depósitos de eventos esporádicos. As estruturas sedimentares que se destacam são as estratificações cruzadas e flaser nos metaquartzo arenitos e laminação nos metargilitos.

\section{Formação Novo Horizonte}

A Formação Novo Horizonte é formada por litofácies vulcânica, subvulcânica, piroclástica e epiclástica, representada por dacito, riolito, quartzo pórfiro e feno andesito (Guimarães et al., 2005). Segundo Guimarães et al. (2005) o conjunto vulcânico/subvulcânico encontra-se modificado pela atuação de fluidos (magmáticos, primários ou secundários), com diversos padrões de alteração hidrotermal (potassificação, propilitização, greisenização e silicificação) e deformação, sendo comum a presença de sericita xistos, sericita-quartzo xistos, milonitos e ultramilonitos, gerados por zonas de cisalhamento. Estão associadas à esta unidade, mineralizações de ouro, barita e quartzo rutilado.

De acordo com Teixeira (2005), as rochas vulcânicas/subvulcânicas da unidade são resultantes de um magmatismo peraluminoso e alcalino do tipo A2, com contribuição crustal, de ambiente anorogênico. Datações de U-Pb realizadas em zircões de metarriolitos fornecem as idades para época do vulcanismo de $1752 \pm 4$ Ma (Schobbenhaus et al., 1994) e 1748 \pm 4 Ma

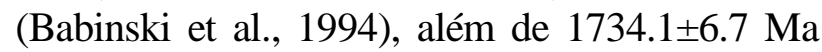
em dacitos porfiríticos (Campos, 2013), relacionando-as à formação do rift Espinhaço. As idades Ar-Ar de 404 \pm 3 e 499 \pm 2 , obtidas por Guimarães et al. (2005), realizadas em muscovita de metarriolitos, atestam a participação do evento orogenético Brasiliano na reestruturação das bacias Espinhaço Oriental e Chapada Diamantina.

Segundo Guimarães et al. (2005), a mineralização de ouro ocorre sob a forma primária (filoniana) e secundária (elúviocoluvionar e aluvionar). Os filões quartzoauríferos são concordantes com as principais estruturas da área, paralelas às zonas de cisalhamento, falhas e fraturas, com direção preferencial NNW-SSE. De acordo com o autor, os veios mineralizados podem ser extensionais ou de cisalhamento, sendo comumente boudinados, resultantes da atuação da tectônica de empurrão. Desta forma, a mineralização pode estar representada por veios ou venulações paralelas entre si ou em arranjos mais caóticos como brechas hidrotermais.

Tectonossequência Lagoa de Dentro/Ouricuri do Ouro

De acordo com Guimarães et al. (2005), a Tectonossequência Lagoa de Dentro/Ouricuri do Ouro é formada por sedimentação continental terrígena, com sistemas aluviais e eólicos para a Formação Ouricuri do Ouro e lacustre para a Formação Lagoa de Dentro.

Litofácies conglomeráticas associam-se a sistemas aluviais e lacustres. Lateral e verticalmente aos conglomerados, ocorrem arenitos mal selecionados e litarenitos, representando depósitos de sistema fluvial entrelaçado de alto gradiente e baixa sinuosidade, evoluído do sistema de leque aluvial. Arenitos bem selecionados, bimodais, com estratificação cruzada relacionam-se a sistema eólico e predominaram na fase final de evolução do rifte (Guimarães et al, 2005).

\section{DEPÓSITO LAVRA VELHA}

O depósito Lavra Velha localiza-se próximo à charneira da estrutura Anticlinal Ibitiara, que representa uma dobra aberta, levemente assimétrica, com vergência para leste e eixo aproximado na direção $\mathrm{N}-\mathrm{S}$, com mergulho suave para NNW (Campos, 2013).
As estruturas que se destacam na área do depósito são falhas reversas, zonas de cisalhamento (sinistral) e dobras, consideradas reflexos das grandes estruturas regionais zonas de cisalhamentos Ibitiara (Cruz, 2004) e Ibiajara (Guimarães et al., 2005). Estas zonas 
de cisalhamento sinistrais apresentam padrão ramificado e, de acordo com estes autores, são responsáveis pelo soerguimento do Granitoide Ibitiara e formação da Anticlinal Ibitiara. As unidades que ocorrem no depósito Lavra Velha são o Granitoide Ibitiara e as formações Novo Horizonte e Ouricuri do Ouro (Campos, 2013 e Carlin, 2013). A mineralização está associada a brechas hidrotermais compostas essencialmente por quartzo e óxido-hidróxido de ferro, podendo conter sulfetos (Campos, 2013). Segundo Campos (2013), elas ocorrem ao longo de planos de fraturas subhorizontais e subverticais em rochas subvulcânica, correspondente ao Granitoide Ibitiara, próximo ao contato com a Formação Novo Horizonte, sendo as principais brechas mineralizadas subhorizontais com direção N10-30E e mergulho suave para NNW.

As rochas encaixantes do depósito Lavra Velha encontram-se intensamente alteradas, principalmente por intensa sericitização e ferro- metassomatismo. Suas texturas e estruturas primárias encontram-se parcialmente preservadas a completamente obliteradas, dificultando a caracterização do protólito.

Datações U-Pb em cristais de zircão (análise por LA-ICP-MS) realizadas por Campos (2013) forneceram idade de 2.093,5 \pm 8,2 Ma para a rocha subvulcânica encaixante da mineralização, $2.161 \pm 50 \mathrm{Ma}$ para uma brecha hidrotermal e 2.165+18Ma para metagabro foliado.

Campos (2013) propõe o modelo IOCG (Iron Oxide Copper Gold Ore Deposits) para o depósito Lavra Velha, sendo este formado por fusão de manto litosférico subcontinental e metassomatizado, com intensa alteração hidrolítica em ambiente de arco magmático (Figura 3). De acordo com o autor, este ambiente é propício para a formação de estruturas transtensivas, que favorecem a intrusão de rochas félsicas e máficas, além da percolação de fluidos hidrotermais.

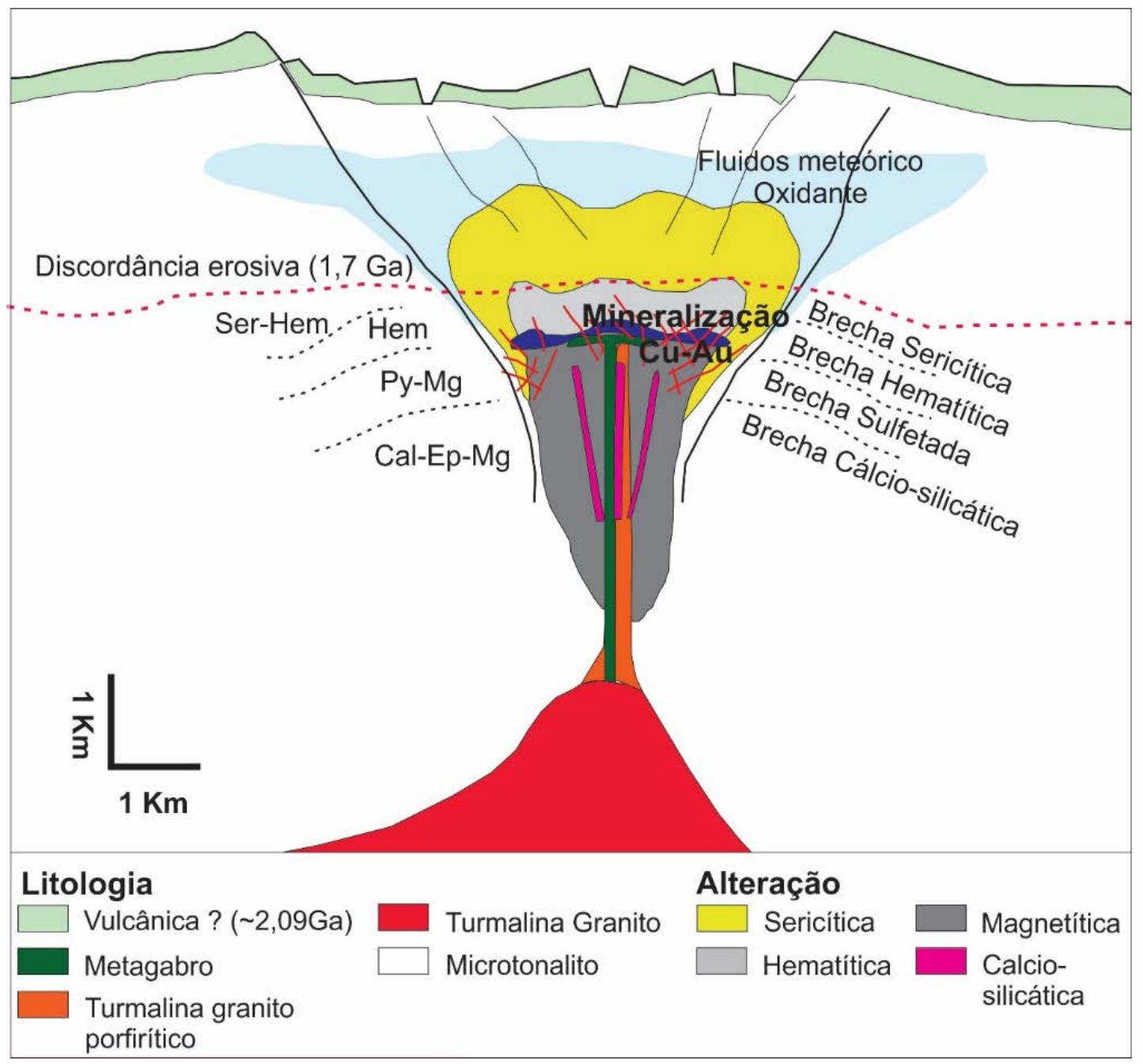

Figura 3 - Modelo do depósito IOCG Lavra Velha, segundo Campos (2013). 


\section{PETROGRAFIA}

Foram analisadas quanto aos aspectos macroscópicos, mesoscópicos e microscópicos 38 amostras (Figura 4), das quais 19 correspondem às rochas encaixantes da mineralização de ouro Lavra Velha, 10 às amostras do Granitoide Ibitiara, 6 ao Granito Matinos e 3 às rochas metavulcânicas da Formação Novo Horizonte.

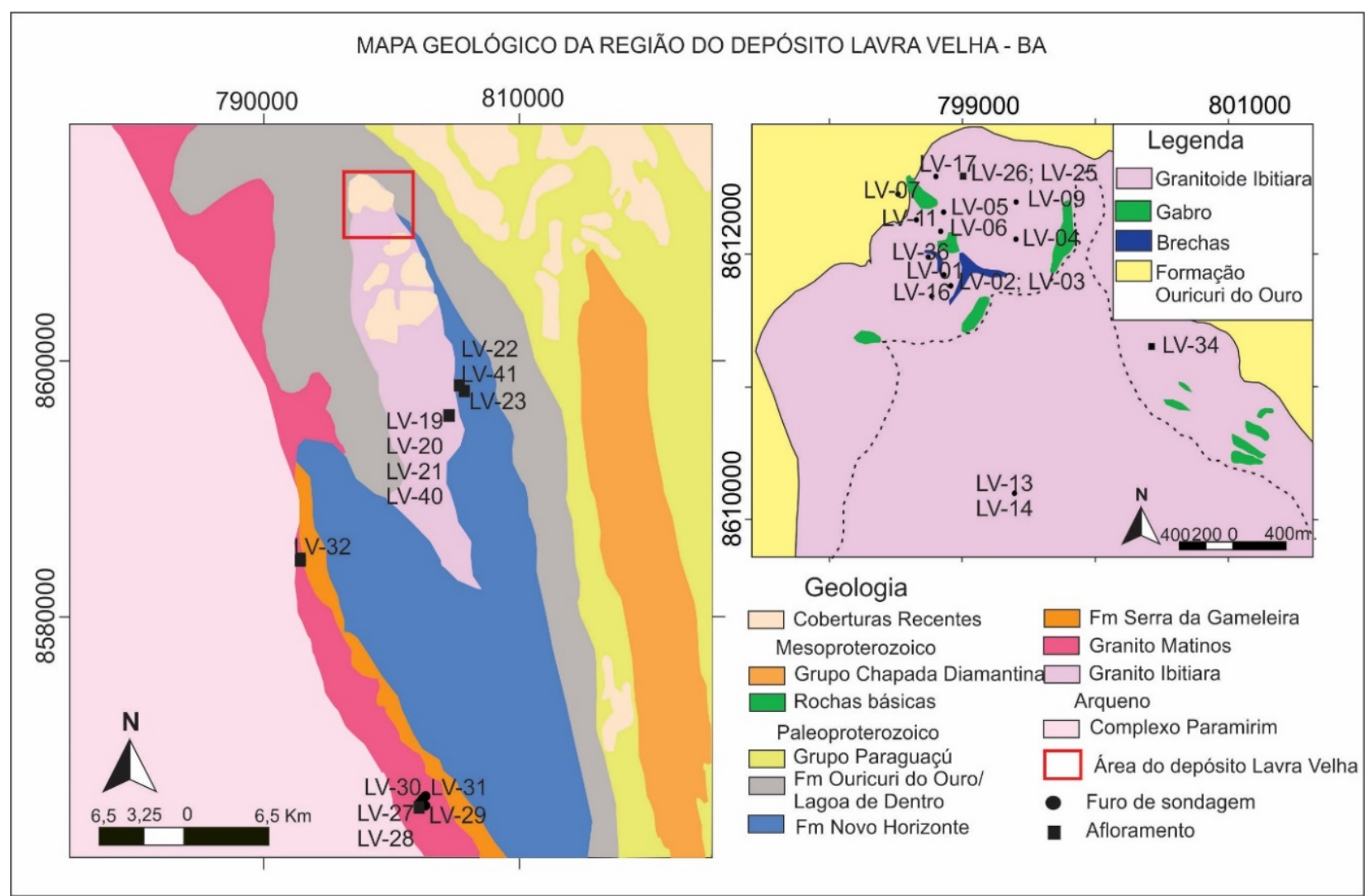

Figura 4 - Mapa de localização das amostras próximo ao município de Ibitiara e depósito Lavra Velha. A figura à direita corresponde ao depósito Lavra Velha, destacada pelo retângulo vermelho na imagem à esquerda.

As rochas encontram-se alteradas e, localmente, com fraca deformação, correspondendo a xistos, gnaisses e granitos alterados e deformados. Contudo, as rochas foram classificadas de acordo com seus respectivos protólitos, interpretados a partir da paragênese secundária.

\section{Granitoide Ibitiara}

O Granitoide Ibitiara é formado por tonalito, granodiorito, meta-quartzo diorito e metaquartzo monzodiorito. Os principais processos de alteração atuantes são sericitização, predominante, cloritização, carbonatação, podendo ocorrer ainda epidotização, albitização e sulfetação subordinada.

Na Rodovia BA-152, que liga a cidade de Ibitiara ao município de Novo Horizonte, localiza-se uma pedreira desativada, onde predominam rochas de composição tonalítica com variação granodiorítica e rochas de composição diorítica, interpretadas como enclaves por Guimarães et al. (2005). As rochas são cortadas por veios e vênulas de quartzo, carbonato, epidoto e, mais raramente, pirita, hematita e magnetita. As rochas aflorantes desta pedreira, apresentam estrutura e textura do protólito relativamente mais preservadas.

As amostras do Granitoide Ibitiara correspondem a metatonalito, metagranodiorito, meta-quartzo diorito e meta-quartzo monzodiorito.

As rochas são predominantemente faneríticas, com coloração cinza e tonalidade esverdeada. Apresentam estruturas isotrópica ou foliada, com granulação inequigranular, variando entre média e fina e estrutura de rocha ígnea (granítica), com textura blastogranular hipidiomórfica preservada. São constituídas por plagioclásio parcial a totalmente alterado, quartzo, feldspato potássico (ortoclásio) 
alterado, sericita, clorita, carbonato, epidoto, minerais opacos e minerais acessórios de apatita, zircão, titanita, allanita e monazita. Os cristais de plagioclásio são inequigranulares, com dimensões entre $0,3 \mathrm{~mm}$ e $2,5 \mathrm{~mm}$, subedrais a anedrais, com forma tabular nas rochas menos deformadas (Figura 5A) e sigmoidal nas mais deformadas. Podem estar saussuritizados e substituídos parcial a completamente por sericita, constituindo os pseudomorfos de plagioclásio sericitizado (Figura 5). Localmente, observa-se geminação albita (Figura 5A).

O quartzo ocorre como cristais anedrais, inequigranulares, com granulação variando entre $0,1 \mathrm{~mm}$ e $2,5 \mathrm{~mm}$, normalmente com disposição intersticial, onde fazem contato lobado com os demais cristais, principalmente com o plagioclásio. Podem exibir leve extinção ondulante e fraturas preenchidas por quartzo e/ou carbonato.

Os cristais de feldspato potássico (ortoclásio) são anedrais, inequigranulares, com granulação variando entre 0,5 e $2,0 \mathrm{~mm}$, e alterados, predominando a sericitização. Observa-se em alguns cristais a estrutura chessboard, típica de albitização. A clorita ocorre como cristais anedrais, com dimensão média ou inferior a 0,2mm, com pleocroísmo

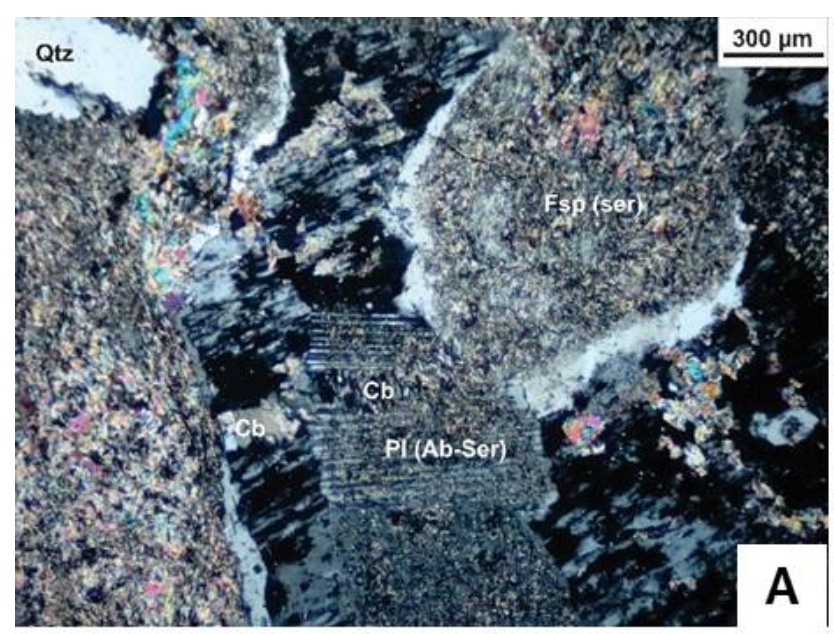

verde escuro - verde pálido, verde amarelado verde escuro ou marrom escuro - amarelo. Associa-se à biotita, muscovita e minerais opacos.

Os cristais de carbonato são anedrais, com granulação inferior a $0,1 \mathrm{~mm}$ a $1,5 \mathrm{~mm}$. Ocorrem em veios e vênulas (Figura 5A) e associados aos cristais de feldspato saussuritizados (Figura 5B).

$\mathrm{O}$ epidoto, semelhante ao carbonato, ocorre principalmente associado ao feldspato saussuritizado e em veios e vênulas. São cristais anedrais a subedrais, com tamanho médio ou inferior a $0,2 \mathrm{~mm}$.

Os minerais opacos predominantes são martitas e magnetitas parcialmente martitizadas, substituídas de 30 a $90 \%$ por hematita, cujos cristais são anedrais a subedrais, com dimensões variando entre 0,2 e $0,02 \mathrm{~mm}$. Os cristais de hematita são anedrais a subedrais de granulação muito fina e ocorrem normalmente disseminados na rocha. Cristais de pirita e/ou calcopirita podem ser observados com granulação muito fina. Hidróxido de ferro associa-se comumente a estes minerais.

Cristais de titanita são subedrais a anedrais, variando entre 0,2 e $1,0 \mathrm{~mm}$, e ocorrem associados aos cristais de feldspato sericitizados e/ou saussuritizados e óxidos/hidróxidos de ferro.

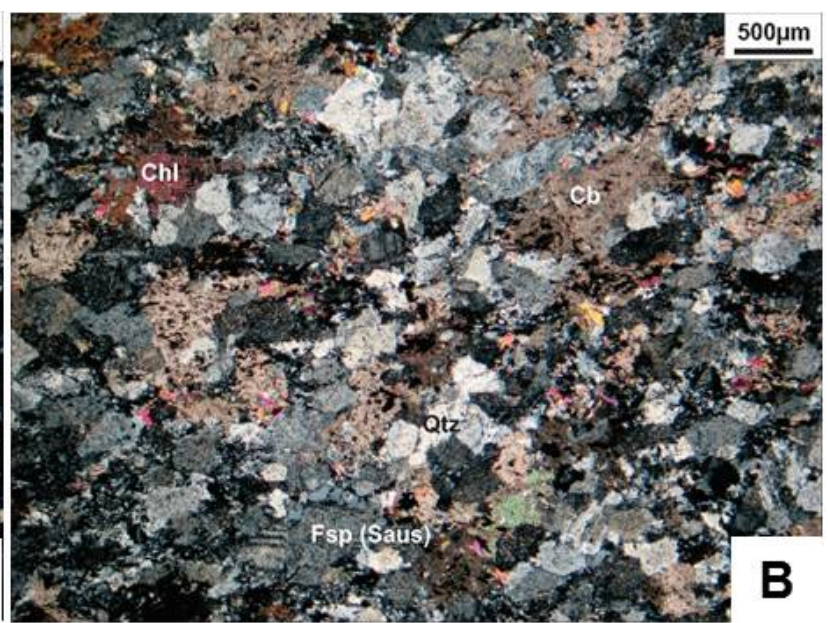

Figura 5 - Fotomicrografias de lâminas delgadas polidas obtidas em microscópio de luz transmitida (polarizadores cruzados). A) Granodiorito com estrutura de rocha ígnea preservada e cristais subedrais de feldspato albitizado e sericitizado. Rocha cortada por veio de carbonato; B) Amostra de meta-quartzo monzodiorito com leve saussurtização e sericitização dos cristais de feldspato. Intensa carbonatação sobre os cristais da rocha.

\section{Rochas Encaixantes do Depósito Lavra Velha}

Assim como no Granitoide Ibitiara, as rochas encaixantes do depósito Lavra Velha são constituídas por uma associação litológica de metatonalito, meta-quartzo diorito e granitos alterados e/ou deformado, referente às amostras intensamente alteradas, principalmente por processos de sericitização, e/ou deformadas, cujos protólitos não foram identificados durante 
a análise petrográfica. Os principais processos hidrotermais atuantes nas rochas são saussuritização, sericitização, cloritização, carbonatação, turmalinização, formação de óxido/hidróxido de ferro e registros de processos de albitização.

Os afloramentos na área do depósito são escassos e encontram-se deformados e alterados por processos intempéricos e hidrotermais. São registradas diferentes intensidades de deformação nas rochas, marcadas principalmente por xistosidade, foliação milonítica, dobras e zonas de fraturas. As rochas apresentam foliação com direção preferencial E-W e forte padrão de faturamento com direções preferenciais entre $\mathrm{NE}$ e $\mathrm{NW}$, com mergulho aproximadamente de $50^{\circ}$ para SE e SW, respectivamente. As fraturas predominam na direção EW e NS, com mergulhos subverticais.

As rochas são cortadas por veios e vênulas de turmalina e quartzo ou quartzo, hematita e/ou magnetita martitizada, comumente associados a hidróxido de ferro. Suas fraturas podem ser preenchidas por brechas hidrotermais, constituídas por quartzo, hematita e magnetita, associadas normalmente à ocorrência do minério de ouro.

As rochas encaixantes do Depósito Lavra Velha apresentam coloração cinza e tonalidades avermelhadas ou esverdeadas, variando entre faneríticas a subfaneríticas, com estrutura predominante foliada. Assim como no Granitoide Ibitiara, apresentam estrutura reliquiar de rocha ígnea (granítica), xistosa e brechada ou cisalhada. As rochas, de modo geral, são inequigranulares, com granulação de fina a média, e suas texturas variam de hipidiomórfica a xenomórfica.

A composição mineralógica destas rochas é formada por cristais de plagioclásio sericitizado, quartzo, feldspato potássico alterado, biotita/clorita, minerais opacos, turmalina, carbonato e minerais acessórios de epidoto, apatita, zircão, rutilo e titanita. As amostras mais deformadas apresentam uma matriz quartzo-sericítica.

O plagioclásio pode variar de cristais subedrais, apresentando formas tabular e/ou sigmoidal (Figura 6A) a anedrais, normalmente orientados paralelo à foliação das rochas (Figura 6). Encontra-se parcial a completamente saussuritizado (Figura 6A) e/ou sericitizado (pseudomorfos) (Figura 6B). O tamanho dos cristais varia entre 0,2 e $5,2 \mathrm{~mm}$ comumente, sendo que nas rochas mais deformadas podem atingir granulação inferior a $0,1 \mathrm{~mm}$.

Os cristais de quartzo são anedrais, arredondados a subangulosos e inequigranulares, com dimensões variando em média entre 0,05 e 5,0mm. Localmente encontram-se recristalizados, com contato entre grãos predominantemente lobulado, podendo apresentar leve extinção ondulante.

Os cristais de quartzo podem ainda estar orientados, estirados ou alongados, paralelos à foliação da rocha e ocorrem comumente nos interstícios ou como porfiroblastos nas rochas porfirítica. Podem constituir camadas descontínuas, com pequenas quantidades de sericita associada, orientadas paralelas à foliação da rocha, delimitadas por filetes de óxido/hidróxido de ferro ou de estilpnomelano, sericita e turmalina.

O feldspato potássico, quando presente, ocorre como cristais anedrais, com tamanho médio de $0,2 \mathrm{~mm}$, parcialmente sericitizado. Podem apresentar textura chessboard.

Nas rochas mais alteradas e deformadas, é difícil distinguir os tipos de feldspato, por apresentar estrutura obliterada devido a deformação e completa, ou quase completa, substituição por minerais secundários. Sua intensa alteração pode resultar em uma matriz de rocha quartzo-sericita associada normalmente a um núcleo sericítico, interpretado como o núcleo dos pseudomorfos (Figura 6B).

A clorita pode apresentar pleocroísmos verde escuro - verde pálido, verde escuro transparente e marrom escuro - verde escuro. Seus cristais, anedrais, ocorrem associados normalmente aos domínios sericíticos, e em algumas amostras associa-se à biotita e, possivelmente, a estilpnomelano.

Os minerais opacos presentes nas rochas são hematita, predominante, martita e magnetita martitizada, magnetitas com inclusões de ilmenita e em pequenas quantidades, quando presente, pirita e/ou calcopirita, e associados normalmente a hidróxido de ferro. Os cristais variam de subedrais a anedrais, com tamanho inferior a $0,1 \mathrm{~mm}$ a $3,5 \mathrm{~mm}$. Ocorrem 
disseminados e em veios, com quartzo e, menos frequente, turmalina. Pode-se ainda observar associados aos minerais opacos, biotita/clorita e estilpnomelano.

Os cristais de carbonato são anedrais e tem dimensões inferiores a $0,2 \mathrm{~mm}$. Associam-se ao feldspato alterado (saussuritização) e ocorre também em veios e vênulas que cortam as rochas.

A turmalina ocorre tanto como cristais disseminados na rocha, quanto em veios, associados normalmente a quartzo, com presença ou não de minerais opacos. São cristais subedrais, que atingem $1,8 \mathrm{~mm}$, na seção longitudinal.

\section{Granito Matinos}

O Granito Matinos localiza-se a oeste do Depósito Lavra Velha, no flanco oeste da Anticlinal Ibitiara. As amostras foram coletadas próximo ao município de Ibiajara, cuja área é afetada por delgadas zonas de cisalhamento dúcteis, de direção NNW-SSE, com mergulhos subverticais para WSW, que catalisam, em associação com hidrotermalismo, a modificação total da textura e mineralogia primária da rocha. Foram coletadas desde amostras pouco alteradas, ou deformadas, localizadas mais distais às zonas de cisalhamento, a amostras intensamente alteradas e deformadas, próximas às zonas de cisalhamento.
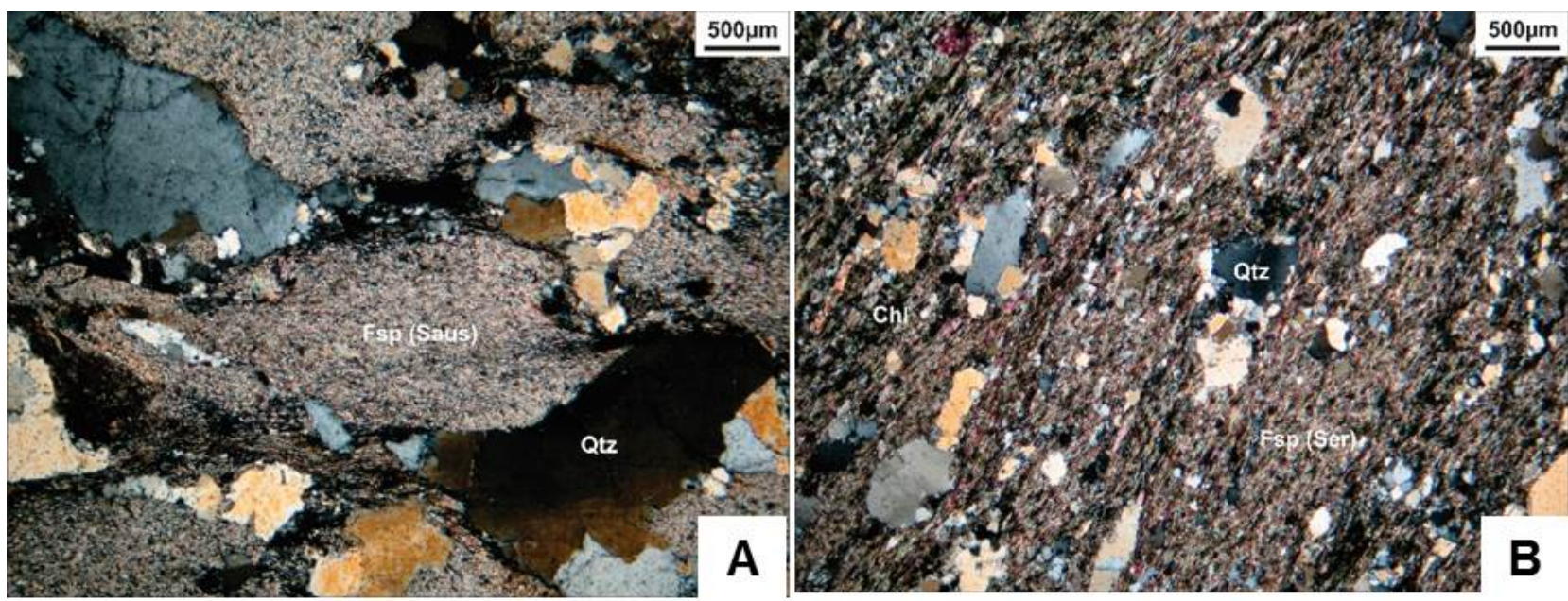

Figura 6 - Fotomicrografias de amostras da rocha encaixante do depósito Lavra Velha (polarizadores cruzados). A) Amostra de tonalito com estrutura de rocha ígnea parcialmente preservada e cristais de feldspato sigmoidais (pseudomorfos) completamente saussuritizados e sericitizadas; B) Amostra de granito deformado, foliado, com cristais de feldspato completamente deformado e sericitizado e matriz quartzo-sericítica.

O Granito Matinos é formado por granodiorito, monzogranito e granito cisalhado, que correspondem às amostras deformadas e intensamente alteradas localizadas mais próximas às zonas de cisalhamento.

As amostras apresentam coloração cinza, com tonalidades róseas a esverdeadas, sendo que as rochas mais deformadas, apresentam cor amarelo ocre ou rosa salmão. As rochas são faneríticas, com exceção das rochas intensamente deformadas pelas zonas de cisalhamento (subfaneríticas a afaníticas) e foliadas.

Microscopicamente, as rochas mais distais à zona de cisalhamento apresentam estrutura de rocha ígnea (granítica) preservada, com textura blastogranular hipdiomórfica e cristais inequigranulares, com granulação variando de média a grossa (Figura 7A). As rochas mais deformadas, incluindo o "granito cisalhado", apresentam estrutura cataclástica a milonítica (Figura 7B). As rochas são constituídas essencialmente por plagioclásio alterado, feldspato alterado e quartzo, com menores quantidades de biotita e/ou clorita, minerais opacos, carbonato e turmalina. Como acessório foram reconhecidos epidoto, apatita e zircão. As amostras de granito cisalhado apresentam os cristais de feldspato completamente sericitizados (pseudomorfos), o que impede, desta maneira, a sua identificação (Figura 7B).

O plagioclásio encontra-se parcialmente sericitizados e/ou saussuritizados, ou completamente sericitizado. No metamonzogranito, os cristais são subedrais, com granulação variando de 0,2 a 3,0mm, enquanto no metagranodiorito, os cristais subedrais a anedrais, variam de 0,3 a $1,0 \mathrm{~mm}$. 
O feldspato potássico mostra grau de alteração incipiente a total para sericita e pode apresentar textura chessboard. Os cristais são subedrais, com dimensões variando entre 0,5 e $1,5 \mathrm{~mm}$ nas amostras de metagranodiorito e 0,2 e $3,0 \mathrm{~mm}$ nas de meta monzogranito.

Nas amostras de granito cisalhado, os cristais de feldspato encontram-se completamente sericitizados (pseudomorfos), assumindo forma sigmoidal, orientados paralelos à foliação da rocha, com dimensões variando entre 0,2 e $1,5 \mathrm{~mm}$ (Figura 7B). Nas rochas mais deformadas e alteradas hidrotermalmente, os cristais de feldspato encontram-se completamente obliterados, resultando em uma matriz de rocha quartzo-sericítica. Os cristais de quartzo podem ocorrer na forma intersticial (Figura 7A) ou granular como cristais anedrais, arredondados a subangulosos, variando de 0,2 a 4,0 mm nas rochas. Observa-se em alguns cristais extinção ondulante. No granito cisalhado, os cristais variam de 0,05 a $1,0 \mathrm{~mm}$ e, além de extinção ondulante, encontram-se localmente fraturados e recristalizados, além de constituírem veios e vênulas que cortam estas rochas. A clorita pode associar-se aos cristais de biotita alterados, muscovita e aos domínios

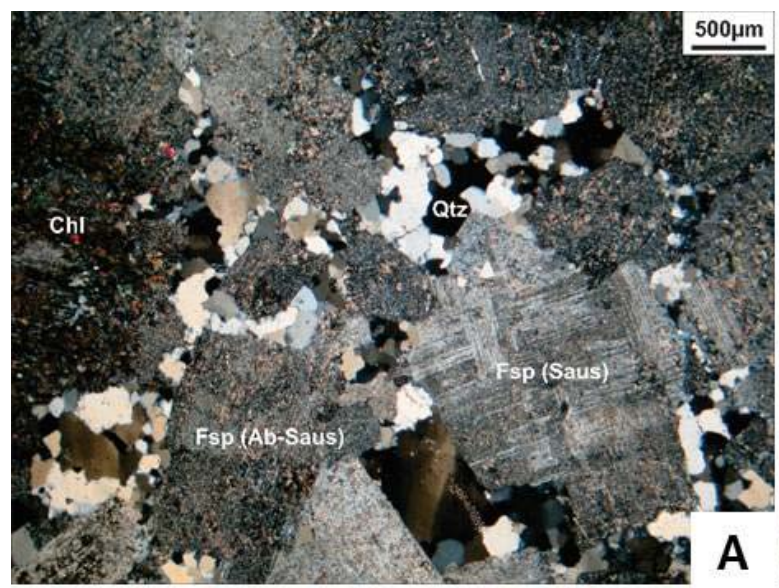

sericíticos, além de epidoto, allanita e minerais opacos. Localmente é intersticial e orientada. Apresenta pleocroísmo verde musgo claro verde escuro e a biotita amarelo - verde musgo.

Os minerais opacos predominantes são magnetitas parcialmente martitizadas e martitas, comumente substituídos por hidróxido de ferro, das bordas para o centro dos cristais, que são anedrais, com dimensões variando entre 0,01 e $0,3 \mathrm{~mm}$. Comumente os minerais são substituídos por hidróxido de ferro. Nos granitos cisalhados ocorrem ainda titanomagnetitas, ilmenitas e, como minerais acessórios, piritas ou calcopirita.

Os cristais de carbonato são anedrais, com tamanho médio de $0,2 \mathrm{~mm}$ associados à sericita e constituintes dos veios que cortam estas rochas, associados normalmente a clorita. Os cristais de turmalina são subedrais, com tamanho médio de $0,3 \mathrm{~mm}$ em suas seções transversais e ocorrem nos domínios sericíticos, disseminadas na rocha.

Algumas amostras de granito cisalhado apresentam filetes formados por estilpnomelano e óxido/hidróxido de ferro, orientados paralelos à foliação, que delimitam as microzonas de cisalhamento.

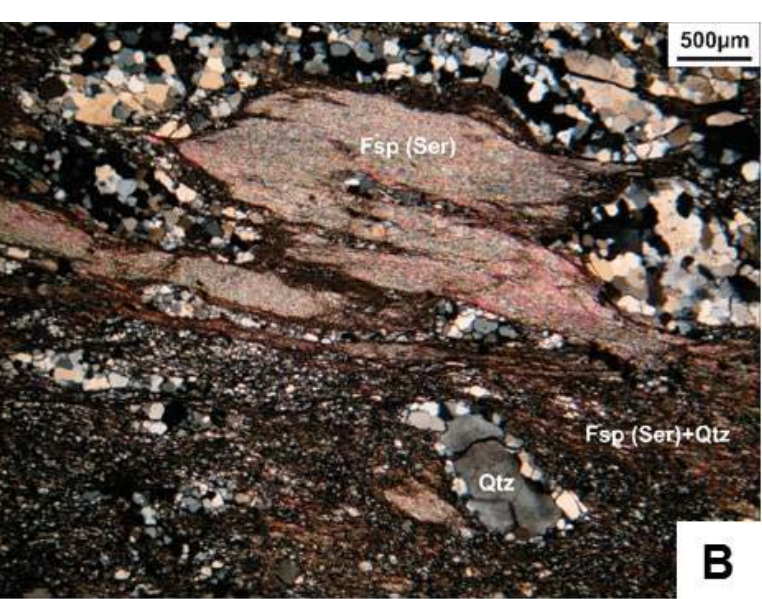

Figura 7 - Fotomicrografias de amostras do Granito Matinos (polarizadores cruzados). A) Metagranodiorito, com estrutura reliquiar de rocha ígnea, cristais de feldspato potássico e plagioclásio saussuritizados, localmente albitizados, e quartzo intersticial recristalizado; B) Amostra do granito milonitizado, com cristais de quartzo recristalizado, feldspato completamente sericitizados (pseudomorfos) e matriz quartzo sericítica.

\section{Formação Novo Horizonte}

A Formação Novo Horizonte é representada, na região próxima do Depósito Lavra Velha, por metadacito pórfiro e metarriolito alterados. Posiciona-se, estratigraficamente, acima do embasamento Granitoide Ibitiara e aflora no flanco leste da Anticlinal Ibitiara e leste do Depósito Lavra Velha.
As amostras foram coletadas em afloramentos, localizados na Serra da Torre, onde metadacito, metarriolito e tufo vulcânico ocorrem intercalados. Veios de quartzo, predominantemente sub-horizontais, cortam estas rochas.

\section{Metadacito Pórfiro}

As amostras de metadacito pórfiro têm 
coloração cinza e tonalidade arroxeada na matriz da rocha afanítica com pseudomorfos de fenocristais de plagioclásio sericitizados brancos milimétricos e fenocristais de quartzo arredondados e azulados. Apresenta estrutura isotrópica e textura blastoporfirítica, constituída por uma matriz de granulação fina quartzosericítica, que compõe em média $75 \%$ a rocha, fenocristais de quartzo (em média 10\%) e de plagioclásio alterados (pseudomorfos), que compõe entre 10 e $15 \%$ da rocha, minerais opacos, que podem atingir $5 \%$ da sua composição, e minerais acessórios representados, principalmente, por epidoto.

A matriz da rocha é composta por cristais de quartzo microgranular, com tamanho médio inferior a $0,02 \mathrm{~mm}$, sericita e minerais acessórios de epidoto, na forma de cristais subedrais com dimensão média de $0,05 \mathrm{~mm}$.

Os fenocristais de plagioclásio encontram-se substituídos por sericita (pseudomorfos), variando de anedral a subeudral (arredondada a subangulosa), e dimensões entre 1 e $5 \mathrm{~mm}$ (Figura 8A). Os fenocristais de quartzo são arredondados ou alongados e tem em média $2 \mathrm{~mm}$ de dimensão. Apresentam uma coroa de reação quartzosa sobre a matriz. Alguns cristais apresentam estrutura de embainhamento, com suas bordas corroídas (Figura 8B).

Os minerais opacos que predominam são hematita, ou magnetita com baixos teores de titânio, com núcleos constituídos por ilmenita, comumente com formas arredondadas e dimensões entre 0,5 e 1,5mm.
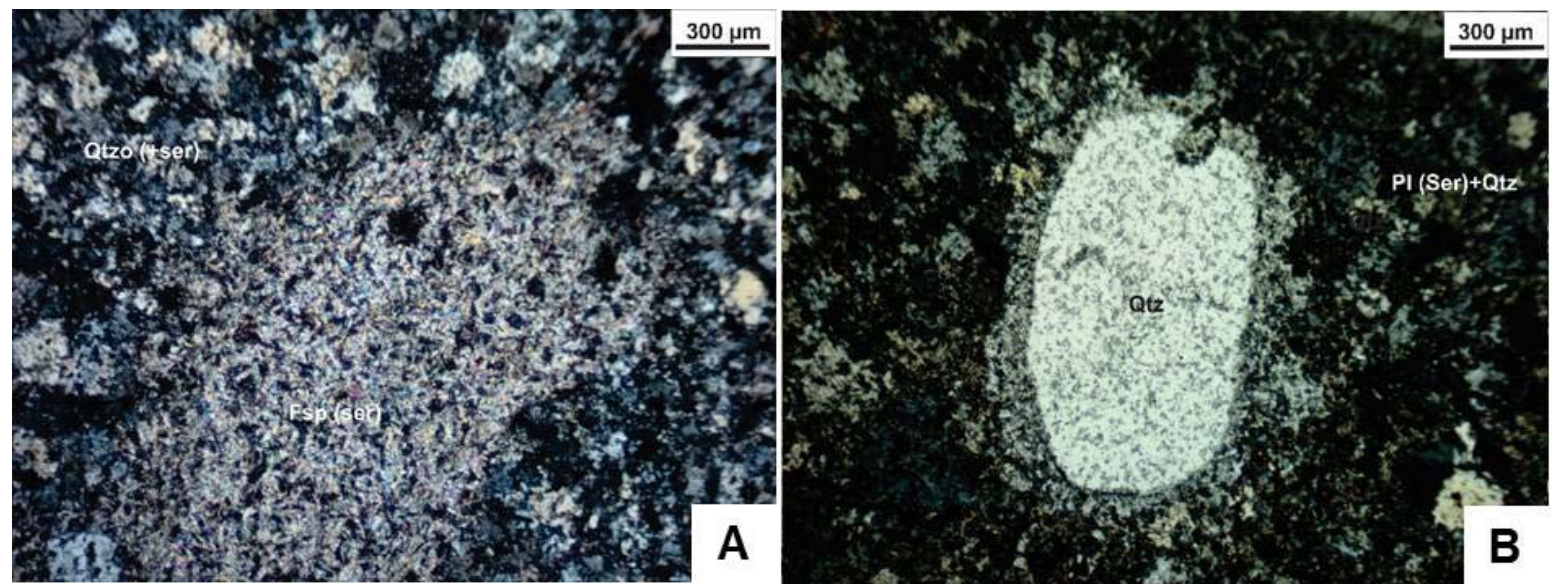

Figura 8 - Fotomicrografias de amostra de metadacito pórfiro (polarizadores cruzados) com fenocristal de plagioclásio (pseudomorfo) completamente seritizado. A) quartzo arredondado, com halo quartzoso e feição de embainhamento, B), típico de rocha vulcânica, envoltos por matriz quartzo sericítica.

\section{Metarriolito}

A amostra de metarriolitos apresenta coloração marrom avermelhada, e encontra-se intensamente alterada. A rocha é compacta, afanítica, de granulação muito fina, com uma estrutura isotrópica, formada por uma matriz composta por quartzo, pirofilita e minerais opacos, com forte alteração de hidróxido de ferro. A pirofilita, identificada por teste de difração de Raios X, compõe aproximadamente $60 \%$ da rocha, sendo a principal constituinte da sua matriz e dos cristais de feldspato completamente alterados (pseudomorfos).

Os cristais de quartzo são anedrais, subangulosos e tem dimensões iguais ou inferiores a 0,2mm. Também constituem a matriz da rocha, tal como a pirofilita, na forma de cristais microgranulares, em menores proporções.

O mineral opaco predominante é hematita, representado por cristais anedrais a subedrais, substituídos parcialmente por hidróxido de ferro.

\section{DISCUSSÕES E CONCLUSÕES}

As rochas encaixantes do depósito Lavra Velha assemelham-se às amostras do Granitoide Ibitiara, tanto pela composição mineralógica, quanto pela estrutura da rocha ígnea reliquiar, parcial a completamente preservada das alterações hidrotermais e deformações atuantes nas rochas.
A albitização encontra-se parcial a completamente obliterada pela sobreposição de sericitização, principalmente. Associados aos cristais, ou pseudomorfos, de feldspato, normalmente sericitizados, também ocorrem cristais microgranulares de epidoto, carbonato e clorita, como produtos de saussuritização, 
sugerindo uma fase concomitante ou tardia à albitização, posteriormente sobreposta pela sericitização.

A alteração dos cristais de magnetita para hematita, que posteriormente associam-se à alteração de hidróxido de ferro, indica que houve mudança do estado de oxidação dos fluidos com a evolução do processo hidrotermal.

A sericitização é o processo hidrotermal predominante, superposta às demais alterações, sendo responsável pela obliteração da mineralogia primária das rochas, relacionada aos estágios mais tardios do hidrotermalismo.

Em exceção, o metarriolito, da Formação Novo Horizonte, tem como alteração hidrotermal tardia e predominante a pirofilitização, resultado provavelmente da completa lixiviação dos minerais de potássio.

Desta maneira, as alterações hidrotermais ocorreram provavelmente nesta ordem: albitização - saussuritização (epidotização/carbonatação/cloritização) - formação de óxido/ hidróxido de ferro - sericitização/turmalinização.

A evolução da modificação da estrutura e composição mineralógica das amostras do Granito Matinos, analisadas de acordo com a sua distância em relação às zonas de cisalhamento, foi comparada às demais amostras das unidades da região do depósito Lavra Velha e auxiliou na compreensão da relação existente entre o Granitoide Ibitiara e as rochas encaixantes do depósito Lavra Velha, permitindo assim sua associação.

\section{AGRADECIMENTOS}

Os autores agradecem ao Programa de Pós-graduação em Geociências e Meio Ambiente do Instituto de Geociências e Ciências Exatas - IGCE/UNESP e a CAPES pela concessão da bolsa de Mestrado à autora.

\section{REFERÊNCIAS}

ALKMIM, F.F.; NEVES, B.B.B.; ALVES, J.A.C. Arcabouço Tectônico do Cráton do São Francisco: uma revisão. In: MISI, A; DOMINGUEZ, J.M.L. O Cráton do São Francisco. Salvador: SBG, 1993, p. 45-62.

ARCANJO, J.B.A.; VARELA, P.H.L.; MARTINS, A.A.M.; LOUREIRO, H.S.C.; NEVES, J.P. Projeto Vale do Paramirim: Estado da Bahia, Escala 1:200.000. Salvador: CPRM. Programa Levantamentos Geológicos Básicos do Brasil - PLGB. Convênio CBPM/CPRM, 105 p., 2000. Relatório interno.

BABINSKI, M.; NEVES; B.B.B.; NOCE; C.M. Problemas da Metodologia U/Pb com Zircões de Vulcânicas Continentais: Caso do Grupo Rio dos Remédios Supergrupo Espinhaço, no Estado da Bahia. In: CONGRESSO BRASILEIRO DE GEOLOGIA, 38, 1994, Balneário de Camboriú. Anais... Balneário de Camboriú: SBG, 1994, n. 2, p. 409-410.

BASTOS LEAL, L.R.; TEIXEIRA, W.; CUNHA, J.C.; MACAMBIRA, M.J.B. Archean tonalitic-tondhjemitic and granitic plutonism in the Gavião Block, São Franciscano Craton, Bahia, Brazil: geochemical and geochronological characteristics. Revista Brasileira de Geociências, v. 28, n. 2, p. 209-220, 1998.

CAMPOS, L.D. O Depósito de Au-Cu Lavra Velha, Chapada Diamantina Ocidental: Um Exemplo de Depósito da Classe IOCG Associado aos Terrenos Paleoproterozoicos do Bloco Gavião. Brasília, 2013. 104p. Dissertação (Mestrado), Instituto de Geociências, Universidade Federal de Brasília.

CARLIN, A.C. Caracterização Petrográfica e Geoquímica das Rochas Encaixantes da Mineralização de Ouro do Alvo Lavra velha - Ibitiara (BA). Rio Claro, 2013. 144p. Trabalho de Conclusão de Curso - Instituto de Geociências, Universidade Estadual Paulista.

CRUZ, S.C.P. A interação tectônica entre o Aulacógeno Paramirim e o Orógeno Araçuaí-Congo. Ouro Preto, 2004. 465p. Tese (Doutorado), Universidade Federal de Ouro Preto.
CRUZ, S.C.P. \& ALKIMIM F.F. The tectonic interaction between the Paramirim Aulacogen and the Araçuai Belt, São Francisco Craton region, Eastern Brazil. Anais da Academia Brasileira de Ciências, v. 78, n. 1, p.151-173, 2006

GUIMARÃES, J.T.; MARTINS, A.A.M.; ANDRADE FILHO, E.L.; LOUREIRO, H.S.C.; ARCANJO, J.B.A.; NEVES J.P.; ABRAM, M.B.; SILVA, M.G.; BENTO, R.V. (Org.). Projeto Ibitiara-Rio de Contas: Estado da Bahia. Salvador: CPRM. Programa Recursos Minerais do Brasil, Escala 1:200.000. Convênio CBPM/CPRM. 193 p., 2005. Relatório Interno.

PEDROSA-SOARES, A.C.; NOCE, C. M.; WIEDMANN, C.; PINTO, C.P. The Araçuaí-West-Congo orogen in Brazil: an overview of a confined orogen formed during Gondwana assembly. Precambrian Research, n. 110, p. 307-323, 2001.

SCHOBBENHAUS, C. As tafrogêneses superpostas Espinhaço e Santo Onofre, Estado da Bahia: revisão e novas propostas. Revista Brasileira de Geociências, v. 26, n. 4, p. 265-276, 1996. SCHOBBENHAUS, C.; HOPPE, A.; BAUMANN, A.; LORCK, A. Idade $\mathrm{U} / \mathrm{Pb}$ do vulcanismo Rio dos Remédios, Chapada Diamantina, Bahia. In: CONGRESSO BRASILEIRO DE GEOLOGIA, n.38, 1994, Balneário Camboriú. Anais... Balneário Camboriú: SBG, 1994, v. 2. p. 397-399.

TEIXEIRA, L.R. Projeto Vale do Paramirim: relatório temático de litogeoquímica. Salvador: CPRM, 2000. Programa Levantamentos Geológicos Básicos do Brasil PLGB. Relatório interno.

TEIXEIRA, L.R. Projeto Ibitiara - Rio de Contas: relatório temático de litogeoquímica. Salvador: CPRM, 2005. 33p. Programa Levantamentos Geológicos Básicos do Brasil PLGB. Relatório interno 